\title{
Qual a Direção da Convergência na Produtividade da Mão de Obra na Agropecuária de Minas Gerais?1
}

\author{
Filipe de Morais Cangussu Pessoa², Marcelo José Braga ${ }^{3}$, \\ Márcio Antônio Salvato ${ }^{4}$ e Daniel Arruda Coronel ${ }^{5}$
}

Resumo: O presente estudo tem como objetivo investigar se existiu um processo de convergência da produtividade da mão de obra no setor agropecuário mineiro, ao longo do período de 1970 a 2006, e em que regióes agropecuárias de baixa produtividade estariam reduzindo o hiato existente em relação às regiões agropecuárias de alta produtividade. Para tal finalidade, desagregou-se o estado em municípios e, como metodologias de teste, utilizaram-se densidades de distribuição e um processo estacionário de primeira ordem de Markov, em sua versão discreta. Os resultados demonstram que as distribuições de produtividade dos municípios sofreram um deslocamento de massa para a esquerda, indicando piora na produtividade, e que sua dinâmica de evolução apresentou um processo de convergência em direção a classes inferiores de produtividade.

Palavras-chaves: Convergência, cadeias de Markov, produtividade, setor agropecuário.

\footnotetext{
Abstract: This study aims to investigate if there is a convergence process of labor productivity in the agricultural sector of Minas Gerais State over the period 1970 to 2006, and in which regions of low agricultural productivity the gap in relation to the regions with high agricultural productivity has been reducing. For this purpose, the state is disaggregated into municipalities, and as testing methodologies are used density

1. Os autores agradecem ao apoio do Conselho Nacional de Desenvolvimento Científico e Tecnológico (CNPq).

2. Doutorando e Mestre em Economia Aplicada pela Universidade Federal de Viçosa (UFV) e Economista do Instituto Federal de Educação, Ciência e Tecnologia de Brasília (IFB). E-mail: filipe_morais_pessoa@yahoo.com.br

3. Coordenador do Programa de Pós-graduação em Economia Aplicada da UFV e Bolsista de Produtividade do CNPq. E-mail: mjbraga@ufv.br

4. Professor Adjunto do Instituto Brasileiro de Mercado de Capitais (IBMEC-MG) e Coordenador do Curso de Ciências Econômicas do IBMEC-MG e Doutor em Economia pela Fundação Getúlio Vargas do Rio de Janeiro (FGV-RJ). E-mail: marcio.salvato@gmail.com

5. Professor Adjunto do Programa de Pós-graduação em Administração, Diretor da Editora da Universidade Federal de Santa Maria (UFSM) e Doutor em Economia Aplicada pela UFV. E-mail: daniel.coronel@uol.com.br
} 
distribution and a first order Markov process in its discrete and continuous versions. The results show that the distributions of productivity of municipalities have suffered mass displacement to the left, indicating a worsening in it and its dynamics of development showed a process of convergence towards the lower classes of productivity.

Key-words: Convergence, Markov chains, labor-productivity, agricultural sector.

Classificação JEL: O47, C14, C21.

\section{Introdução}

O setor agropecuário brasileiro, a partir da década de 1960, pode ser caracterizado pela intensificação do uso de insumos, máquinas e equipamentos modernos, aspecto que se desenvolveu impulsionado pelo pacote tecnológico conhecido como Revolução Verde. O consórcio desses fatores com os edafoclimáticos (clima, solo e condições do tempo) favoráveis criou condições propícias para o incremento e a sustentação de taxas positivas de crescimento da oferta de produtos agropecuários de alta qualidade e a custos menores. A utilização dessas novas tecnologias resultou em ganhos expressivos de produtividade agrícola no Brasil, conforme mostrado por Gasques et al. (2004), Vicente (2006) e Gonçalves (2007), e favoreceram a diversificação e a ampliação da produção em todas as regiões do país.

Concomitante a tal quadro, verifica-se, nas últimas décadas, no Brasil, um êxodo rural expressivo. Mais especificamente em Minas Gerais, a população rural, como porcentagem da população urbana, segundo dados divulgados pela Secretaria de Estado de Agricultura, Pecuária e Abastecimento (SEAPA, 2010), passou de 32,1\%, em 1980, para 15,3\% em 2006, dinâmica típica de uma economia em crescimento (GOLLIN et al., 2002; YANG e ZHU, 2008). Assim, para a agropecuária do estado cumprir com as funções estabelecidas pelas políticas macroeconômica e setorial, como oferta crescente de alimentos para consumo doméstico, ampliação do mercado para produtos da indústria, expansão da oferta da poupança e geração de divisas externas, devido ao declínio de sua mão de obra, é imprescindível aumentar a produtividade deste fator. Além disso, a elevação da produtividade da mão de obra do setor agropecuário mineiro neste processo se faz necessária tendo em vista a preocupação de elevar a renda do trabalhador rural, para que este tenha incentivo em permanecer no campo (STULP, 2004).

Os trabalhos de Gasques e Conceição (2000) e Freitas, Bacha e Fossati (2007) apontaram o aumento da produtividade da mão de obra na agropecuária mineira a partir da década de 1970, o que revela o resultado de políticas governamentais voltadas para a modernização do setor.

Como informa Curi (1997), dentre as ações de política de modernização do setor agropecuário mineiro, destacam-se os programas de incorporação de terras baratas do cerrado ao processo produtivo, financiados e comandados pelo poder público durante o período 1960-1980, e a reestruturação do arcabouço institucional responsável pela condução da política agrícola (crédito rural subsidiado para aquisição de máquinas, equipamentos e fertilizantes agrícolas; preços mínimos de garantia; pesquisa e assistência técnica).

Contudo, esse processo de modernização não ocorreu de maneira uniforme, visto que contemplou regiões e produtos distintos, o que, 
de certa forma, agravou a heterogeneidade do desenvolvimento agrário no estado, levando a uma situação de modernização parcial. Isto porque os instrumentos de política utilizados tinham abrangência nacional e adotaram um pacote tecnológico relativamente inflexível, que não se adequava ao perfil de todos os produtores rurais, principalmente o do produtor mineiro, e essa falta de flexibilidade foi grandemente responsável pelo crescimento das disparidades regionais (MEYER e BRAGA, 1998).

Do exposto, verifica-se que há, apesar do crescimento da produtividade da mão de obra na agropecuária, em Minas Gerais, um quadro de disparidades entre suas regiões, impulsionado principalmente por um processo de modernização agrícola que não contemplou todo o estado. Diante desse contexto, tem-se o arcabouço fundamental que justifica a análise, qual seja, investigar se por trás deste aumento de produtividade e das disparidades existentes no estado há uma tendência de regióes com baixa produtividade estarem reduzindo o hiato existente entre as regiões com alta produtividade, embasado no processo de convergência advogado pela literatura de crescimento econômico. Nesse âmbito, o estudo dessa variável assume um papel importante, já que "é uma estatística sintética útil acerca do nível de desenvolvimento econômico no sentido que está altamente correlacionada com outros indicadores de qualidade de vida" (JONES, 2000, p. 3).

Apesar de existirem trabalhos na literatura nacional que estudaram o processo de convergência em Minas Gerais ${ }^{6}$, poucos são os voltados para o setor agropecuário 7 . Em vista disso, o presente trabalho visa preencher essa lacuna, utilizando como metodologias de análise densidades de distribuição e matrizes de transição de

6. Por exemplo, Alves e Fontes (2001), Pimentel e Haddad (2004), Silva et al. (2005), Figueirêdo, Leal Filho e Aguiar (2006) e Salvato et al. (2006).

7. Caldeira et al. (2010) analisam convergência no setor agropecuário mineiro no período de 1996 a 2006, utilizando como variável de estudo o PIB agropecuário per capita com base nas metodologias de teste de $\beta$-convergência absoluta e condicional e os testes de Quah (1993) e Drennan e Lobo (1999).
Markov. Essa abordagem refina as metodologias de $\beta$ e $\sigma$-convergência, tradicionalmente utilizadas para tal finalidade, ao fornecer informação do formato de toda a distribuição de produtividade da mão de obra e de como ela evolui.

O artigo está estruturado em três seções, além desta introdução. Na segunda seção, são apresentados os procedimentos metodológicos; na terceira seção, os resultados obtidos são analisados e discutidos e, por fim, são apresentadas algumas considerações finais.

\section{Metodologia}

\subsection{Densidades de distribuição}

A literatura de crescimento econômico iniciou a aplicação de densidades de distribuição para análise da evolução da produtividade (QUAH, 1993) visando contornar as deficiências das metodologias tradicionalmente empregadas para o estudo de convergência, principalmente no que tange à ausência de informação intradistribuição, já que as regressões cross-section e o cômputo de dispersão revelam informações médias da amostra como um todo, não sendo possível captar particularidades de suas porções.

Esta análise pode ser feita pela discretização do espaço de produtividades, por meio da construção de histogramas, os quais permitem uma visualização gráfica das frequências relativas. $\mathrm{Na}$ construção do histograma, as economias ${ }^{8}$ analisadas são agrupadas em intervalos de produtividade de tamanho fixo. Em seguida, contam-se quantas economias pertencem a cada intervalo e desenha-se uma barra proporcional ao número contado. Um problema existente na discretização de um espaço contínuo é a possibilidade de obtenção de resultados diferentes, dependendo da origem ou do tamanho dos intervalos escolhidos (GONDIM e BARRETO 2004).

8. Economias aqui e ao longo do presente estudo devem ser entendidas como regiões agropecuárias. 
Para evitar as distorções produzidas pela discretização, pode-se estimar uma densidade de distribuição pelo método de suavização por núcleo (kernel smoothing). Este método considera cada economia de uma amostra de tamanho $\mathrm{n}$ o ponto central de um intervalo de tamanho h. No presente contexto, utilizou-se uma função de ponderação com núcleo Gaussiano.

$\mathrm{Na}$ análise das densidades, uma curva mais concentrada (leptocúrtica) indica uma maior convergência, ao passo que uma curva mais achatada (platicúrtica) indica maior dispersão da produtividade, portanto, maior divergência. Além disso, permite-se a identificação de moda(s) e, consequentemente, características como estratificação e polarização. Estes dois termos foram cunhados em Quah (1997). O primeiro denota a formação de dois grupos opostos (duas modas na distribuição), um de alta renda e outro de baixa renda, e o segundo denota uma situação em que não só dois grupos, mas diversos (mais de duas modas na distribuição) são formados.

\subsection{Processo estacionário de primeira ordem de Markov}

O cálculo de densidades de distribuição carece, contudo, de informações quanto ao mecanismo que gera uma determinada evolução da distribuição. Tem-se uma distribuição no período t e outra no período $t+1$, mas não se sabe a dinâmica responsável por transformar tal distribuição entre os períodos.

Para preencher esta lacuna, Quah $(1992,1993)$ utiliza um processo estacionário de primeira ordem de Markov por meio de matrizes de transição, o qual é capaz de gerar uma "lei de movimento" que revele como a distribuição evolui no tempo.

Trata-se de um sistema de equações em diferenças, em que a solução será a condição da economia no seu estado estacionário, após a convergência/divergência da produtividade, ou seja,

$$
Y_{t+1}=M^{\prime} Y_{t}
$$

em que $Y$ é um vetor linha de produtividades em dois períodos de tempo distintos; $\mathrm{M}$, descreve a transição de um vetor de produtividades para outro.

Em outras palavras, $\mathrm{M}$ pode ser interpretada como uma matriz de probabilidades de transição: para quaisquer duas classes de produtividade i e $\mathrm{j}$ $(i, j \in C)$, em que $C$ denota o conjunto de todas as classes de produtividade, os elementos $M_{i j}$ definem a probabilidade de se mover de uma classe i para uma classe $\mathrm{j}$ entre os períodos de tempo $\mathrm{t}$ e $t+1$, já a diagonal principal representa a probabilidade de se permanecer na mesma classe. Suponha-se que uma economia $r$ está na classe $\mathrm{i}\left(\mathrm{Y}_{\mathrm{r}}^{\mathrm{t}} \in \mathrm{i}\right)$ no tempo $\mathrm{t}$, se a seqüência $\left\{\mathrm{Y}_{\mathrm{r}}^{0}, \mathrm{Y}_{\mathrm{r}}^{1}, \ldots\right\}$ satisfaz a relação

$$
\operatorname{Pr}\left\{Y_{r}^{\mathrm{t}+1} \in \mathrm{i} / \mathrm{Y}_{\mathrm{r}}^{\mathrm{t}}, \mathrm{Y}_{\mathrm{r}}^{\mathrm{t}-1}, \ldots \mathrm{Y}_{\mathrm{r}}^{0}\right\}=\operatorname{Pr}\left\{\mathrm{Y}_{\mathrm{r}}^{\mathrm{t}-1} \in \mathrm{i} / \mathrm{Y}_{\mathrm{r}}^{\mathrm{t}}\right\}
$$

para qualquer $i \in C$, e para qualquer economia, então a evolução da distribuição de produtividades Y descrita pela Equação (1) pode ser analisada como um processo estacionário de primeira ordem de Markov. ${ }^{9}$

A matriz de probabilidades de transição de níveis de produtividade é construída pelo uso da razão desta variável em relação à média do estado. Dessa forma, a média estadual passa a ser um, e as economias têm suas posições relativas classificadas por essa média, obedecendo a classes relativas de níveis de produtividade. $\mathrm{O}$ intuito deste procedimento é possibilitar a classificação das duas distribuições ( $\mathrm{t}$ e $t+1)$ em um mesmo intervalo de classes. Mediante a organização das duas distribuições em uma mesma estrutura de classes, será possível examinar como

9. Conforme observam Quah (1992) e Magrini (1999), a definição do processo de Markov na equação (2) não é trivial, já que ela implica que a probabilidade de transição entre quaisquer dois estados (classes de produtividade, no presente caso) é independente do tempo. A suposição de homogeneidade temporal pode parecer forte, tendo em vista que políticas e condições econômicas mudam ao longo do tempo, implicando mudanças nas probabilidades de transição. Contudo, esta suposição é equivalente a analisar convergência em direção ao estado estacionário rodando regressões (de seção cruzada ou série temporal) ao longo de períodos delimitados de tempo. O principal objetivo de todas estas abordagens não é o de fornecer previsões acuradas do futuro, mas sim, de esclarecer a natureza do processo de desenvolvimento econômico que caracteriza a região sob estudo, ao longo do período de análise. 
as economias migram de uma classe para outra. Com base nessas migrações, será construída a matriz de probabilidades de transição de Markov (MAGRINI, 1999).

O grande desafio neste tipo de abordagem é definir um critério de construção da matriz de Markov que não seja arbitrário a ponto de retirar a propriedade markoviana do processo. No presente estudo, será utilizado o critério de Magrini (1999), que é uma alternativa ao método de Quah (1992), o qual busca determinar as classes de forma a se ter um número uniforme de representações entre as classes, contudo, "[...] they are totally subjective and may represent a source of potential problems given that inappropriate discretisation can remove the Markov property from a first-order Markov process" (CHUNG, 1960 apud MAGRINI, 1999). O critério de Magrini (1999) baseia-se em elementos estatísticos e será descrito em detalhes adiante.

Neste critério, antes de estabelecer a construção da matriz de Markov, procede-se ao teste de normalidade Kolmogorov-Smirnov de cada uma das duas distribuições de produtividade da mão de obra agropecuária para as economias em análise (municípios mineiros). Os testes de normalidade são necessários, uma vez que a construção das classes de níveis de produtividade requer a hipótese de normalidade ${ }^{10}$ da distribuição dos dados, necessária para estabelecer sua amplitude, a qual será denominada $h$.

O valor de h, ou seja, a amplitude de classe é importante para a estimativa da função densidade de probabilidade. Existe um trade-off para a escolha de h. Uma amplitude de classe muito grande faz com que haja grande número de pontos em cada intervalo, perdendo informação importante à respeito da dinâmica interna da distribuição. Com uma amplitude de classe pequena, aumenta-se a possibilidade de ter classes de produtividade que não se comunicam, inviabilizando a montagem da matriz. Dessa forma, o valor de $\mathrm{h}$ deve ser escolhido para se

10. Para Magrini (1999), o critério seria válido mesmo em situações onde as observações não seguissem uma distribuição normal. fazer uma escolha ótima para o trade-off entre perda de dinâmica interna e perda de comunicação entre as classes de produtividade.

De acordo com Magrini (1999), quando a distribuição é normal, o valor ótimo do intervalo de classe é dado por $\mathrm{h}=2,72 \mathrm{~s} \mathrm{n}^{-1 / 3}$, em que s é o desvio-padrão da distribuição e $n$, o número de observações.

Definidas as classes de produtividade, pode-se estimar a matriz de transição, de Markov, a partir de um estimador de máxima verossimilhança da probabilidade de transição, comparando o número de economias que pertencem a certa classe no período t e migram para outras classes ou permanecem na mesma, no período $\mathrm{t}+1$.

Como critério de convergência, pode-se afirmar que haverá convergência quando a norma dos autovalores reais ou complexos de $M_{t}$ for menor que a unidade. Como as somas das linhas da matriz de Markov $M_{t}$ têm que ser 1, pois trata-se de uma matriz de probabilidades, obtém-se sempre um autovalor 1. Portanto, sempre haverá convergência para um ou mais vetores de distribuição de produtividade da mão de obra agropecuária. A presença de um único autovalor unitário e dos demais com norma menor que 1 indica que se tem um processo de convergência para uma única distribuição de probabilidade que será linear no autovetor correspondente ao autovalor unitário. Com esse vetor de convergência, pode-se descrever a estrutura da produtividade da mão de obra agropecuária, à qual tende a evolução temporal do processo estocástico (SIMON e BLUME, 2004).

Definida a matriz de Markov M, procede-se à solução do sistema de equações $(1)^{11}$. Ademais, pode-se estimar a velocidade com que o equilíbrio de longo prazo é alcançado através da segunda raiz característica. Essa velocidade representa o tempo necessário para percorrer a metade da distância entre a posição inicial e a de equilíbrio de longo prazo (dm), denominado na literatura de meia-vida. Algebricamente, tem-se

11. Para maiores detalhes ver Simon e Blume (2004). 
$\mathrm{dm}=-\log 2 / \log \left|\mathrm{r}_{2}\right|$, em que $\mathrm{r}_{2}$ é o segundo maior autovalor (MAGRINI, 1999).

A utilização de matriz de probabilidades de transição para modelar a "lei de movimento" é bastante aceita na literatura. Segundo Bulli (2001), a teoria que embasa esta metodologia é acessível e consolidada. Além disso, a estimação da matriz é computacionalmente simples e os resultados são fáceis de interpretar e serem apresentados.

A maior crítica que esta abordagem sofre reside no fato de discretizar um espaço contínuo, o que, se feito de maneira inapropriada, pode distorcer ou mesmo retirar a propriedade de Markov do processo e, além disso, como no caso do histograma, pode produzir resultados diferentes dependendo dos intervalos escolhidos na construção das classes de produtividade. A fim de aperfeiçoar a forma de gerar a "lei de movimento", evitando a discretização dos dados, Quah (1997) recorre ao uso de núcleo estocástico para estimar a probabilidade de transição. ${ }^{12}$

\subsection{Procedimentos utilizados e fonte de dados}

$\mathrm{Na}$ análise empírica, a variável produtividade da mão de obra na agropecuária foi construída para os municípios de Minas Gerais, nos anos de 1970, 1975, 1980, 1985, 1996 e 2006. Os anos foram selecionados segundo critério de disponibilidade de dados, já que, nestes anos, foram realizados censos agropecuários nacionais.

Para os propósitos do estudo, definiu-se produtividade da mão de obra na agropecuária como a razão entre o valor total adicionado da agropecuária (R\$ do ano 2000 deflacionado pelo deflator implícito do produto interno bruto nacional (PIB)) e o total do pessoal ocupado na agropecuária. Este procedimento é o mesmo utilizado por Stulp (2004) e Fochezatto e Stulp (2008). Toda a análise desenvolvida para os municípios foi pautada na variável produtividade relativa da mão de

12. Realizaram-se as estimações dos núcleos estocásticos para o presente contexto, contudo, tendo em vista não ter-se obtido alterações qualitativas nos resultados, optou-se por não reportá-los aqui. Tais resultados podem ser obtidos junto aos autores. obra na agropecuária, que é a razão entre a produtividade da mão de obra dos municípios e a média do estado. De acordo com Le Gallo (2001), é preferível trabalhar em termos relativos ao invés de absolutos para que comovimentos e tendências sejam retirados da série.

Em função do aumento no número de municípios $^{13}$ ao longo do período de estudo, foi preciso uma compatibilização dos dados. Esta compatibilização foi efetuada com base no histórico de emancipações municipais. Desta forma, municípios emancipados ao longo do período de 1970 a 2006 foram incorporados aos de origem.

Os dados de valor total adicionado da agropecuária e total do pessoal ocupado na agropecuária foram obtidos junto ao Instituto de Pesquisa Econômica Aplicada - dados macroeconômicos e regionais (IPEADATA, 2011) referentes aos Censos Agropecuários dos anos de 1970, 1975, 1980, 1985, 1996 e 2006, publicados pelo Instituto Brasileiro de Geografia e Estatística (IBGE).

\section{Análise e discussão dos resultados}

\subsection{Primeiras Evidências}

A Figura 1 apresenta a disposição espacial da produtividade relativa ${ }^{14}$ da mão de obra na agropecuária para os municípios mineiros com base em cinco intervalos de produtividade e seis pontos distintos do tempo, quais sejam, 1970, 1975, 1980, 1985, 1996 e 2006. Esta sequência temporal deve ser lida, na figura, da esquerda para a direita.

Para a primeira faixa de produtividade, vê-se que sua localização predominante está na região Norte do estado, característica que se mantém ao longo dos anos selecionados. Outro movimento marcante é a redução do número de municípios

13. Em 1970, Minas Gerais possuía 722 municípios, já em 2006, esse número foi para 853 .

14. Como a produtividade da mão de obra está normalizada pela média do estado o valor de 0,5 na legenda de cada gráfico refere-se à metade da média estadual, o valor de 2 , a duas vezes a média do estado e assim por diante. 
na segunda faixa, em detrimento dos municípios da primeira faixa na porção Norte, Centro-Leste e Sudeste do estado.

A terceira e quarta faixas estão situadas, em sua maior parte, nas regiões Oeste e Sul do estado, contudo, no decorrer do período, os municípios da região Sul passam a pertencer à segunda faixa, e os municípios da região Oeste, na quarta faixa, passam para a terceira e quinta faixas. Outro movimento que se torna mais nítido, com o passar dos anos, é a separação que ocorre entre regiões de baixa produtividade e média/alta produtividade. No primeiro grupo, situam-se as regiões Norte, Nordeste, Leste, Centro-Leste e Sudeste e, no segundo grupo, estão as regiões Noroeste, Oeste, Centro-Oeste, Sudoeste e Sul.

Figura 1. Disposição espacial da produtividade relativa da mão de obra na agropecuária dos municípios de Minas Gerais, nos anos de 1970 (a), 1975 (b), 1980 (c), 1985 (d), 1996 (e), e 2006 (f)
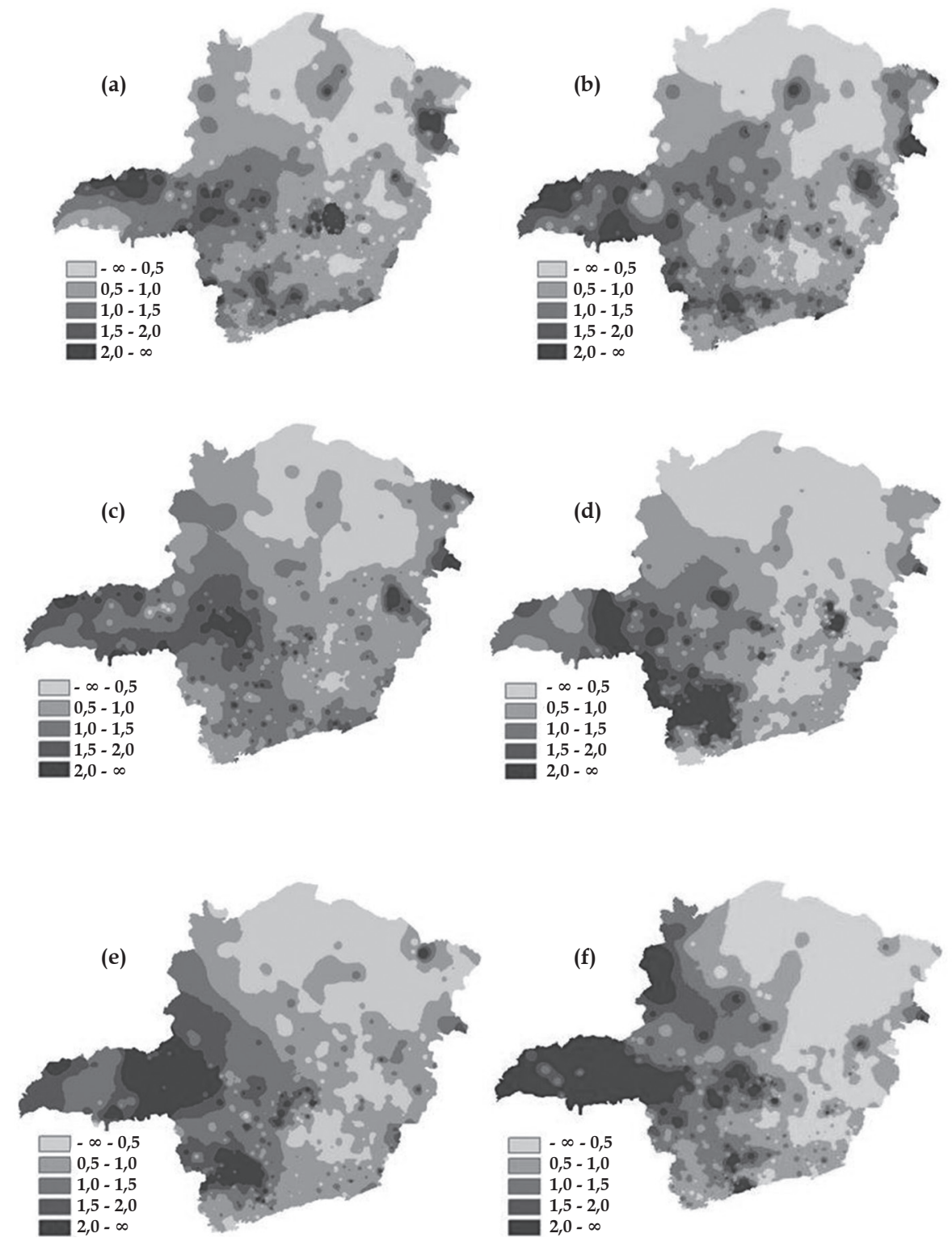

Fonte: Resultados da pesquisa. 
De maneira geral, o que se nota, por este tipo de análise, é que economias situadas na

- primeira faixa de produtividade, permanecem nesta;

- segunda faixa de produtividade, migram para a primeira;

- terceira e quarta faixa, migram para a quinta faixa, contudo, este movimento contempla poucas economias, sendo significativo somente no extremo-oeste do estado.

Se as faixas um e dois de produtividade (que estão abaixo da média do estado) tivessem um peso reduzido na composição do total do pessoal ocupado na agropecuária, poder-se-ia avaliar o quadro acima esboçado como um indício de que estas regiões estariam experimentando um processo de industrialização que, gerando incentivos à migração da agropecuária para outros setores, tenderia a reduzir a importância daquele setor e, consequentemente, o impacto dessa dinâmica para a população local. Contudo, ao longo dos anos selecionados, essas faixas contemplaram, em média, $65 \%{ }^{15}$, do total da população ${ }^{16}$ ocupada nesse setor.

Tendo em vista o exposto acima, nota-se que as primeiras evidências da análise espacial da produtividade relativa da mão de obra na agropecuária, ao longo do estado, sugerem que não há um processo de convergência, em que regiões de baixa produtividade estariam alcançando regiões de alta produtividade, dado que a dicotomia existente entre, principalmente, a porção Norte/ Nordeste do estado e sua porção Oeste/Sudoeste/ Sul, tende a se manter e aumentar ao longo do período de análise.

\subsection{Densidades de distribuição}

A Figura 2 mostra as densidades ${ }^{17}$ da produtividade relativa ${ }^{18}$ da mão de obra na agropecuária dos municípios mineiros para os anos de 1970, 1975, 1980, 1985, 1996 e 2006. A figura deve ser lida em sequência horizontal. Cada gráfico compara as densidades do período inicial (em negrito, começando em 1970) e o período final, 2006 (em pontilhado), o que possibilita visualizar o movimento das densidades de distribuição ao longo do período analisado em cada janela de transição.

$\mathrm{Na}$ análise desta figura, uma densidade mais concentrada (leptocúrtica) indica uma maior convergência, enquanto que uma densidade mais achatada (platicúrtica) indica maior dispersão das produtividades, consequentemente, maior divergência.

A primeira característica que emerge é a predominância de uma distribuição unimodal, com deslocamento para a esquerda em todos os períodos, sendo a exceção, o período de 1985 a 2006, que apresenta um ganho de massa na cauda direita superior ao da cauda esquerda. Outra característica percebida pela análise da Figura 2 é a presença de pequenas modas na extremidade da cauda direita das distribuições, sugerindo um indício de polarização entre regiões de alta e baixa produtividade.

Em geral, a dinâmica que parece estar ocorrendo em grande parte dos municípios mineiros é de convergência para classes inferiores de produtividade relativa da mão de obra na agropecuária. Entretanto, ainda não é possível identificar em que estratos de produtividade estão ocorrendo as migrações que levaram a este fenômeno, o que é necessário para que se possa fornecer uma possível explicação.

17. Estas densidades foram estimadas pelo método de suavização do núcleo gaussiano conforme descrito no referencial analítico.

18. Como a produtividade da mão de obra está normalizada pela média do estado, o valor de 0,5 no eixo horizontal de cada gráfico refere-se à metade da média estadual, o valor de 2 , a duas vezes a média do estado e assim por diante. 
Isso ocorre porque a análise das densidades revela o comportamento da população de produtividades nos períodos selecionados sendo, basicamente, estática ao comparar densidades entre dois pontos no tempo, portanto, carece de uma "lei de movimento" que seja capaz de elucidar a dinâmica que leva a uma ou outra dis- tribuição. São municípios de alta produtividade que deixam de sê-lo, ou municípios de baixa produtividade que agravam ainda mais sua situação? Existe persistência na distribuição? Onde ela é mais acentuada? Visando preencher esta lacuna, apresenta-se os resultados da subseção seguinte.

Figura 2. Evolução das densidades de distribuição da produtividade relativa da mão de obra na agropecuária entre os municípios de Minas Gerais, no período de 1970 a 2006 (a), 1975 a 2006 (b), 1980 a 2006 (c), 1985 a 2006 (d) e 1996 a 2006 (e)
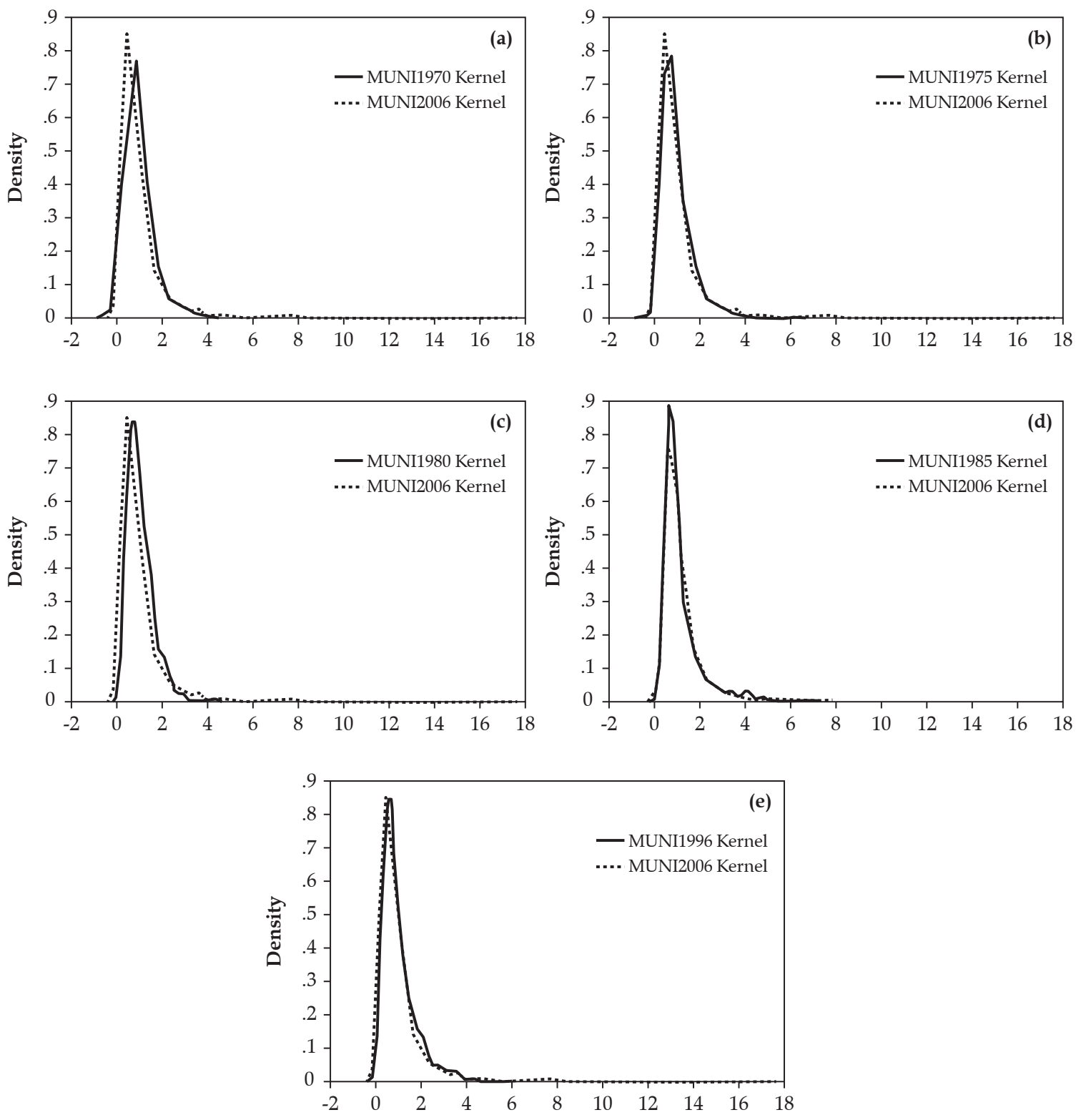

Fonte: Dados da pesquisa. 


\subsection{Matrizes de transição de Markov}

Para o teste de normalidade de KolmogorovSmirnov, adotando-se o nível de significância de $1 \%$, os resultados indicam que nenhuma das distribuições de produtividade relativa da mão de obra na agropecuária de Minas Gerais segue uma distribuição normal ${ }^{19}$. Mesmo diante desse resultado, adotou-se o procedimento de Magrini (1999) para o cálculo do intervalo de classes, seguindo a sugestão desse autor de que o método se ajusta mesmo em observações que não sigam uma distribuição normal.

Com base nas classes de produtividade obtidas é que foram estimadas as matrizes de transição de Markov representadas na Tabela 1. Ao analisá-la, o que se nota é uma alta probabilidade de municípios que estavam na primeira classe no período inicial permanecerem nesta mesma classe no período final, qualquer que seja o período em questão. Tal fato mostra que, ao longo do período sob estudo, pouca mobilidade existe para os municípios situados no extremo inferior da distribuição.

Outro resultado demonstrado pelas estimativas contidas na Tabela 1 é a predominância de probabilidades mais altas abaixo da diagonal principal da matriz, o que denota que, quando existe transição, essa ocorre com maior chance para classes inferiores.

Após a construção das matrizes de transição de Markov, pode-se resolver o sistema de equações em diferenças que irá gerar a trajetória das classes de produtividade até o estado estacionário. A Tabela 2 faz essa exposição mostrando a distribuição no período inicial, até três iterações à frente e no estado estacionário.

Em geral, os municípios estão migrando para a classe mais inferior de produtividade, classe um. No ano de 1970, esta classe possuía 23,82\% dos municípios, em 2006, 37,34\% e no estado estacionário passa a ter $42,16 \%$. Essa dinâmica permanece inalterada para os períodos 1975 a 2006,

19. Este resultado foi omitido por questões de espaço e pode ser obtido junto aos autores.
1980 a 2006 e 1996 a 2006, o que revela que o setor não está conseguindo propiciar uma perspectiva de que sua trajetória de crescimento esteja voltada para classes superiores de produtividade (acima da média do estado).

Esse resultado torna-se mais acentuado ao se analisar todas as classes que estão abaixo da média estadual. Ter-se-ia, no estado estacionário, $72,68 \%, 74,49 \%, 68,44 \%, 51,54 \%$ e $74,89 \%$ dos municípios ocupando tais classes, para os períodos 1970 a 2006, 1975 a 2006, 1980 a 2006, 1985 a 2006 e 1996 a 2006, respectivamente.

No cálculo de meia-vida, o período que apresentou o menor valor foi 1996 a 2006, e o de maior valor foi 1970 a 2006. Nesses casos, levar-se-iam 15 e 44 anos, respectivamente, para que metade do caminho até o estado estacionário fosse percorrido.

Stulp (2004), ao analisar convergência da produtividade da mão de obra na agropecuária gaúcha, no período de 1975 a 1996, encontrou resultados distintos dos aqui apresentados em termos da direção em que ocorrem as migrações. Das quatro classes identificadas, obteve-se uma dinâmica que aponta para uma migração das regiões que ocupam as classes abaixo da média estadual (classes 1 e 2) em direção a classe 3 (acima da média do estado), e migração da classe 4 para a classe 3 . Ainda assim, no estado estacionário, têm-se $62 \%$ das regiões ocupando as classes abaixo da média do estado. Para o cálculo de meia-vida, esse autor encontra o valor de 49 anos, bem próximo dos valores aqui obtidos, principalmente para o período de transição de 1975 a 2006. Fochezatto e Stulp (2008), estudando convergência da produtividade da mão de obra na agropecuária entre os estados brasileiros, no período de 1990 a 2000, identificam quatro classes de produtividade. O resultado aponta para ocorrência de divergência entre os estados, pois cresce o número de estados que participam das classes 1 e 4. Para o cálculo de meia-vida, obteve-se o valor de 7 anos, um valor bem baixo, indicando que os estados já estão bem próximos de sua distribuição de longo prazo. 
Tabela 1. Matrizes de transição de Markov para os municípios de Minas Gerais no período de 1970 a 2006

\begin{tabular}{|c|c|c|c|c|c|c|c|c|c|c|c|c|c|c|c|c|c|c|c|}
\hline \multicolumn{20}{|c|}{$1970-2006$} \\
\hline \multicolumn{4}{|c|}{1} & \multicolumn{2}{|l|}{2} & 3 & & 4 & \multicolumn{2}{|c|}{5} & \multirow{2}{*}{\multicolumn{2}{|c|}{$\begin{array}{l}6 \\
0\end{array}$}} & 7 & \multicolumn{3}{|c|}{8} & 9 & & 10 \\
\hline $1(176)$ & & 0,62 & & 0,26 & & 0,08 & &, 02 & 0,0 & & & & 0 & & 0,01 & & 0 & & 0,01 \\
\hline $2(280)$ & & 0,38 & & 0,36 & & 0,13 & &, 07 & 0,0 & & 0,01 & & 0,01 & & 0,01 & & 0 & & 0,01 \\
\hline $3(152)$ & & 0,2 & & 0,36 & & 0,27 & &, 06 & 0,0 & & 0,03 & & 0,01 & & 0 & & 0,01 & & 0,03 \\
\hline $4(068)$ & & 0,06 & & 0,32 & & 0,28 & &, 09 & 0,0 & & 0,07 & & 0,01 & & 0,06 & & 0 & & 0,04 \\
\hline $5(021)$ & & 0,1 & & 0,24 & & 0,19 & & 0,1 & 0,1 & & 0,05 & & 0,05 & & 0 & & 0,1 & & 0,05 \\
\hline $6(013)$ & & 0 & & 0,08 & & 0,31 & & 31 & 0,0 & & 0 & & 0,15 & & 0 & & 0 & & 0,08 \\
\hline $7(005)$ & & 0 & & 0 & & 0,4 & & 0 & 0,2 & & 0 & & 0,2 & & 0 & & 0 & & 0,2 \\
\hline $8(004)$ & & 0,25 & & 0 & & 0,25 & &, 25 & 0 & & 0,25 & & 0 & & 0 & & 0 & & 0 \\
\hline $9(001)$ & & 0 & & 1 & & 0 & & 0 & 0 & & 0 & & 0 & & 0 & & 0 & & 0 \\
\hline $10(02)$ & & 0,5 & & 0,5 & & 0 & & 0 & 0 & & 0 & & 0 & & 0 & & 0 & & 0 \\
\hline & & & & & & & & & $1975-2$ & 006 & & & & & & & & & \\
\hline & 1 & & 2 & 3 & & 4 & 5 & & 6 & 7 & & & 9 & 10 & & 11 & 12 & & 13 \\
\hline $1(073)$ & 0,6 & & 0,26 & 0,03 & & 0,01 & 0,03 & & 5 & 0,01 & & & 0 & 0 & & 0 & 0 & & 0 \\
\hline $2(168)$ & 0,3 & & 0,38 & 0,15 & & 0,06 & 0,04 & & & 0,02 & & & 0 & 0,0 & & 0,01 & 0 & & 0 \\
\hline $3(177)$ & 0,1 & & 0,31 & 0,23 & & 0,14 & 0,08 & & 04 & 0,02 & & & 0,02 & 0,0 & & 0,01 & 0,01 & & 0,01 \\
\hline $4(126)$ & 0,0 & & 0,26 & 0,29 & & 0,17 & 0,08 & & 03 & 0,04 & & & 0 & 0,0 & & 0,01 & 0,01 & & 0,02 \\
\hline $5(057)$ & 0,0 & & 0,29 & 0,21 & & 0,21 & 0,16 & & 07 & 0,02 & & & 0 & 0 & & 0 & 0 & & 0,02 \\
\hline $6(047)$ & 0 & & 0,24 & 0,24 & & 0,15 & 0,13 & & 5 & 0,07 & & & 0 & 0 & & 0,02 & 0,02 & & 0,09 \\
\hline $7(029)$ & 0,1 & & 0,1 & 0,21 & & 0,14 & 0,14 & & 07 & 0,03 & & & 0,1 & 0 & & 0 & 0 & & 0,1 \\
\hline $8(012)$ & 0 & & 0 & 0 & & 0,25 & 0,08 & & & 0,25 & & & 0,08 & 0 & & 0 & 0 & & 0,08 \\
\hline $9(012)$ & 0,0 & & 0,08 & 0,08 & & 0,33 & 0,08 & & ) & 0 & & & 0 & 0 & & 0 & 0 & & 0,33 \\
\hline $10(05)$ & 0 & & 0 & 0,2 & & 0 & 0 & & & 0,4 & & & 0 & 0 & & 0 & 0,2 & & 0 \\
\hline $11(08)$ & 0 & & 0 & 0 & & 0,25 & 0,25 & & 25 & 0 & & & 0 & 0,2 & & 0 & 0 & & 0 \\
\hline $12(02)$ & 0 & & 0 & 0,5 & & 0 & 0,5 & & 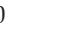 & 0 & & & 0 & 0 & & 0 & 0 & & 0 \\
\hline $13(06)$ & 0 & & 0,17 & 0 & & 0 & 0,17 & & ) & 0,33 & & & 0 & 0,1 & & 0 & 0 & & 0,17 \\
\hline & & & & & & & & & 1980-2 & & & & & & & & & & \\
\hline & 1 & & 2 & & 3 & 4 & & 5 & 6 & & 7 & & & 9 & & 10 & 11 & & 12 \\
\hline $1(036)$ & 0 & & 0,17 & & 06 & 0,06 & & 0 & 0,0 & & 0 & 0 & & 0 & & 0 & 0 & & 0,03 \\
\hline $2(135)$ & 0 , & & 0,33 & & 14 & 0,07 & & 0,01 & 0,0 & & 0,01 & & & 0 & & 0 & 0 & & 0 \\
\hline $3(184)$ & 0 , & & 0,37 & & 2 & 0,12 & & 0,09 & 0,0 & & 0,03 & 0 & & 0,01 & & 0,01 & 0 & & 0,01 \\
\hline $4(130)$ & 0 , & & 0,25 & & 25 & 0,19 & & 0,07 & 0,0 & & 0,02 & & & 0,02 & & 0,01 & 0 & & 0,01 \\
\hline $5(099)$ & 0 , & & 0,19 & & 23 & 0,12 & & 0,15 & 0,0 & & 0,05 & & & 0 & & 0,01 & 0,01 & & 0,09 \\
\hline $6(061)$ & ( & & 0,13 & & 21 & 0,16 & & 0,15 & 0,0 & & 0,05 & & & 0,05 & & 0,02 & 0,03 & & 0,07 \\
\hline $7(030)$ & ( & & 0,17 & & 1 & 0,2 & & 0,3 & 0,0 & & 0 & & & 0,03 & & 0,03 & 0,03 & & 0,1 \\
\hline $8(023)$ & 0 , & & 0,17 & & 09 & 0,13 & & 0,09 & 0,1 & & 0 & & & 0,04 & & 0,09 & 0 & & 0,17 \\
\hline $9(010)$ & 0 & & 0 & & 1 & 0,1 & & 0,1 & 0,2 & & 0 & & & 0,1 & & 0 & 0 & & 0,2 \\
\hline $10(05)$ & ( & ) & 0 & & 0 & 0 & & 0,4 & 0,2 & & 0,2 & & & 0 & & 0 & 0 & & 0,2 \\
\hline $11(04)$ & ( & ) & 0 & & 25 & 0,25 & & 0,25 & 0 & & 0 & & & 0,25 & & 0 & 0 & & 0 \\
\hline $12(05)$ & ( & ) & 0 & &, 2 & 0 & & 0 & 0 & & 0 & & & 0 & & 0 & 0,2 & & 0,4 \\
\hline & & & & & & & & & 1985-? & 006 & & & & & & & & & \\
\hline & 1 & 2 & 3 & 4 & 5 & 6 & 7 & 8 & 9 & 10 & 11 & 12 & 13 & 14 & 15 & 16 & 17 & 18 & 19 \\
\hline $1(174)$ & 0,59 & 0,28 & 0,09 & 0,03 & 0,01 & 0 & 0 & 0 & 0 & 0 & 0 & 0 & 0 & 0 & 0 & 0 & 0 & 0 & 0 \\
\hline $2(257)$ & 0,25 & 0,4 & 0,16 & 0,1 & 0,03 & 0,01 & 0,02 & 0,01 & 0 & 0,01 & 0 & 0 & 0 & 0 & 0 & 0 & 0 & 0 & 0 \\
\hline $3(119)$ & 0,06 & 0,28 & 0,21 & 0,15 & 0,12 & 0,07 & 0,02 & 0,03 & 0,02 & 0,01 & 0,01 & 0 & 0,01 & 0 & 0,01 & 0 & 0 & 0 & 0,02 \\
\hline $4(056)$ & 0,04 & 0,27 & 0,21 & 0,18 & 0,05 & 0,02 & 0,05 & 0,04 & 0,04 & 0,04 & 0 & 0,02 & 0,04 & 0 & 0 & 0 & 0 & 0 & 0,02 \\
\hline $5(029)$ & 0,03 & 0,17 & 0,31 & 0,24 & 0 & 0,03 & 0,1 & 0 & 0 & 0,03 & 0 & 0 & 0 & 0,03 & 0 & 0 & 0 & 0 & 0,03 \\
\hline $6(021)$ & 0 & 0,19 & 0,19 & 0,33 & 0,05 & 0,1 & 0 & 0 & 0 & 0 & 0,05 & 0 & 0 & 0 & 0 & 0 & 0 & 0 & 0,1 \\
\hline $7(013)$ & 0 & 0,15 & 0,46 & 0 & 0,08 & 0,15 & 0 & 0 & 0,08 & 0 & 0 & 0 & 0,08 & 0 & 0 & 0 & 0 & 0 & 0 \\
\hline $8(010)$ & 0 & 0,1 & 0,3 & 0 & 0,2 & 0,2 & 0 & 0 & 0,1 & 0 & 0 & 0 & 0 & 0 & 0 & 0 & 0 & 0 & 0,1 \\
\hline $9(010)$ & 0 & 0 & 0,2 & 0,4 & 0,1 & 0,2 & 0 & 0,1 & 0 & 0 & 0 & 0 & 0 & 0 & 0 & 0 & 0 & 0 & 0 \\
\hline $10(05)$ & 0 & 0,2 & 0,4 & 0 & 0,2 & 0,2 & 0 & 0 & 0 & 0 & 0 & 0 & 0 & 0 & 0 & 0 & 0 & 0 & 0 \\
\hline $11(10)$ & 0 & 0,2 & 0,5 & 0,1 & 0,1 & 0 & 0 & 0 & 0,1 & 0 & 0 & 0 & 0 & 0 & 0 & 0 & 0 & 0 & 0 \\
\hline $12(02)$ & 0 & 0 & 0 & 0,5 & 0 & 0,5 & 0 & 0 & 0 & 0 & 0 & 0 & 0 & 0 & 0 & 0 & 0 & 0 & 0 \\
\hline $13(05)$ & 0 & 0 & 0,2 & 0,6 & 0 & 0,2 & 0 & 0 & 0 & 0 & 0 & 0 & 0 & 0 & 0 & 0 & 0 & 0 & 0 \\
\hline $14(01)$ & 0 & 0 & 1 & 0 & 0 & 0 & 0 & 0 & 0 & 0 & 0 & 0 & 0 & 0 & 0 & 0 & 0 & 0 & 0 \\
\hline $15(02)$ & 0 & 0 & 0,5 & 0 & 0,5 & 0 & 0 & 0 & 0 & 0 & 0 & 0 & 0 & 0 & 0 & 0 & 0 & 0 & 0 \\
\hline $16(01)$ & 0 & 0 & 1 & 0 & 0 & 0 & 0 & 0 & 0 & 0 & 0 & 0 & 0 & 0 & 0 & 0 & 0 & 0 & 0 \\
\hline $17(02)$ & 0 & 0 & 0,5 & 0 & 0 & 0 & 0,5 & 0 & 0 & 0 & 0 & 0 & 0 & 0 & 0 & 0 & 0 & 0 & 0 \\
\hline $18(01)$ & 0 & 1 & 0 & 0 & 0 & 0 & 0 & 0 & 0 & 0 & 0 & 0 & 0 & 0 & 0 & 0 & 0 & 0 & 0 \\
\hline $19(04)$ & 0,25 & 0 & 0,5 & 0,25 & 0 & 0 & 0 & 0 & 0 & 0 & 0 & 0 & 0 & 0 & 0 & 0 & 0 & 0 & 0 \\
\hline
\end{tabular}




\begin{tabular}{|c|c|c|c|c|c|c|c|c|c|c|c|c|c|c|c|}
\hline \multicolumn{16}{|c|}{ 1996-2006 } \\
\hline & 1 & 2 & 3 & 4 & 5 & 6 & 7 & 8 & 9 & 10 & 11 & 12 & 13 & 14 & 15 \\
\hline $1(117)$ & 0,61 & 0,27 & 0,07 & 0,03 & 0,01 & 0 & 0 & 0,01 & 0 & 0 & 0,01 & 0 & 0 & 0 & 0 \\
\hline $2(218)$ & 0,23 & 0,48 & 0,15 & 0,08 & 0,04 & 0,01 & 0 & 0 & 0 & 0 & 0 & 0 & 0 & 0 & 0 \\
\hline $3(131)$ & 0,15 & 0,39 & 0,24 & 0,08 & 0,06 & 0,02 & 0,02 & 0,01 & 0,02 & 0 & 0,01 & 0 & 0 & 0 & 0,01 \\
\hline $4(84)$ & 0,01 & 0,20 & 0,34 & 0,26 & 0,09 & 0,05 & 0,02 & 0,01 & 0 & 0,01 & 0 & 0 & 0 & 0 & 0 \\
\hline $5(62)$ & 0,05 & 0,11 & 0,16 & 0,24 & 0,16 & 0,05 & 0,03 & 0,05 & 0,06 & 0,02 & 0 & 0,02 & 0 & 0,02 & 0,03 \\
\hline $6(40)$ & 0 & 0,10 & 0,23 & 0,25 & 0,05 & 0,08 & 0,08 & 0,05 & 0 & 0,03 & 0,03 & 0,03 & 0 & 0 & 0,10 \\
\hline $7(20)$ & 0 & 0,10 & 0,10 & 0,20 & 0,05 & 0,25 & 0,10 & 0 & 0 & 0 & 0,10 & 0 & 0,05 & 0 & 0,05 \\
\hline $8(11)$ & 0 & 0 & 0,08 & 0,00 & 0,31 & 0,31 & 0 & 0,08 & 0 & 0,15 & 0 & 0 & 0 & 0 & 0,08 \\
\hline $9(13)$ & 0 & 0 & 0,27 & 0,09 & 0,09 & 0,18 & 0 & 0 & 0,09 & 0 & 0 & 0 & 0 & 0,09 & 0,18 \\
\hline $10(8)$ & 0 & 0,13 & 0,25 & 0,13 & 0,13 & 0 & 0,25 & 0 & 0 & 0,13 & 0 & 0 & 0 & 0 & 0 \\
\hline $11(9)$ & 0 & 0 & 0,22 & 0,33 & 0 & 0,11 & 0 & 0 & 0,11 & 0 & 0 & 0,11 & 0 & 0 & 0,11 \\
\hline $12(1)$ & 0 & 0 & 0,50 & 0 & 0 & 0 & 0 & 0,50 & 0 & 0 & 0 & 0 & 0 & 0 & 0 \\
\hline $13(3)$ & 0 & 0 & 0 & 0,50 & 0,50 & 0 & 0 & 0 & 0 & 0 & 0 & 0 & 0 & 0 & 0 \\
\hline $14(1)$ & 0 & 0 & 1,00 & 0 & 0 & 0 & 0 & 0 & 0 & 0 & 0 & 0 & 0 & 0 & 0 \\
\hline $15(4)$ & 0 & 0 & 0 & 0,50 & 0,25 & 0 & 0,25 & 0 & 0 & 0 & 0 & 0 & 0 & 0 & 0 \\
\hline
\end{tabular}

Nota: Os valores entre parênteses indicam o número de municípios em cada classe no período inicial.

Fonte: Resultados da pesquisa

Diante dos resultados expostos, pode-se responder às questões levantadas ao final da subseção 3.2. São municípios de alta produtividade que deixam de sê-lo, ou municípios de baixa produtividade que agravam ainda mais sua situação? Pela dinâmica obtida com a solução do sistema de equações em diferenças, percebe-se que ambos os movimentos ocorrem, ou seja, municípios de baixa produtividade migram para classes de produtividade ainda mais baixas e municípios de classes de produtividade intermediária e elevada também. Isso se torna claro pela redução geral no percentual de municípios contidos nas classes de produtividade que não a classe 1 e pelo incremento desta. Cabe ressaltar que a redução nas classes mais elevadas é modesta se comparada à redução nas classes mais baixas.
Percebe-se também a existência de persistência na distribuição, sendo mais acentuada nas classes inferiores de produtividade. Isso se tornou evidente pelas altas probabilidades nas primeiras entradas da matriz de Markov.

Uma possível explicação para esta persistência é a discrepância existente na implantação da política de modernização do setor agropecuário mineiro (crédito rural subsidiado; preços mínimos de garantia; pesquisa e assistência técnica). Como destacam Ferreira Júnior et al. (2004), a utilização desses instrumentos contemplou regiões e produtos distintos no território do estado e contribuiu para acentuar ainda mais a heterogeneidade do desenvolvimento agrário, pois levou a uma situação de modernização parcial. 
Tabela 2. Dinâmica das classes de produtividade relativa da mão-de-obra na agropecuária entre os municípios de Minas Gerais em direção ao equilíbrio de longo prazo no período de 1970 a 2006

\begin{tabular}{|c|c|c|c|c|c|c|c|c|c|c|c|c|c|c|c|}
\hline \multicolumn{8}{|c|}{$1970-2006$} & \multicolumn{8}{|c|}{$1975-2006$} \\
\hline \multicolumn{3}{|c|}{$\begin{array}{c}\text { Classes de } \\
\text { Produtividade }\end{array}$} & \multicolumn{5}{|c|}{$\begin{array}{c}\text { Períodos } \\
\text { (cada período se refere a intervalo de } 36 \text { anos) }\end{array}$} & \multicolumn{3}{|c|}{$\begin{array}{c}\text { Classes de } \\
\text { Produtividade }\end{array}$} & \multicolumn{5}{|c|}{$\begin{array}{c}\text { Períodos } \\
\text { (cada período se refere a intervalo de } 31 \text { anos) }\end{array}$} \\
\hline & $\mathbf{L i}$ & Ls & Inicial & 1 & 2 & 3 & $\begin{array}{c}\text { Estado } \\
\text { Estacionário }\end{array}$ & & $\mathbf{L i}$ & Ls & Inicial & 1 & 2 & 3 & $\begin{array}{c}\text { Estado } \\
\text { Estacionário }\end{array}$ \\
\hline $1-$ & - & 0,49 & $23,82 \%$ & $37,34 \%$ & $38,94 \%$ & $40,81 \%$ & $42,16 \%$ & $1-$ & - & 0,31 & $10,11 \%$ & $17,52 \%$ & $23,43 \%$ & $26,80 \%$ & $32,06 \%$ \\
\hline $2-$ & 0,49 & 0,97 & $39,34 \%$ & $27,62 \%$ & $31,00 \%$ & $30,62 \%$ & $30,52 \%$ & $2-$ & 0,31 & 0,62 & $23,27 \%$ & $28,62 \%$ & $28,23 \%$ & $28,32 \%$ & $28,63 \%$ \\
\hline $3-$ & 0,97 & 1,46 & $21,05 \%$ & $18,04 \%$ & $14,99 \%$ & $14,37 \%$ & $13,86 \%$ & $3-$ & 0,62 & 0,93 & $24,52 \%$ & $19,43 \%$ & $16,60 \%$ & $15,47 \%$ & $13,80 \%$ \\
\hline $4-$ & 1,46 & 1,94 & $9,42 \%$ & $6,64 \%$ & $5,63 \%$ & $5,41 \%$ & $5,22 \%$ & $4-$ & 0,93 & 1,24 & $17,45 \%$ & $11,72 \%$ & $10,30 \%$ & $9,49 \%$ & $8,28 \%$ \\
\hline $5-$ & 1,94 & 2,43 & $2,91 \%$ & $3,37 \%$ & $3,41 \%$ & $3,19 \%$ & $3,02 \%$ & $5-$ & 1,24 & 1,55 & $8,03 \%$ & $7,46 \%$ & $7,52 \%$ & $7,10 \%$ & $6,35 \%$ \\
\hline $6-$ & 2,43 & 2,92 & $1,80 \%$ & $2,38 \%$ & $1,72 \%$ & $1,61 \%$ & $1,51 \%$ & $6-$ & 1,55 & 1,86 & $6,37 \%$ & $3,85 \%$ & $3,54 \%$ & $3,26 \%$ & $2,84 \%$ \\
\hline $7-$ & 2,92 & 3,4 & $0,69 \%$ & $1,28 \%$ & $1,18 \%$ & $1,06 \%$ & $0,95 \%$ & $7-$ & 1,86 & 2,17 & $4,02 \%$ & $3,85 \%$ & $3,79 \%$ & $3,55 \%$ & $3,07 \%$ \\
\hline $8-$ & 3,4 & 3,89 & $0,55 \%$ & $1,08 \%$ & $0,78 \%$ & $0,78 \%$ & $0,77 \%$ & $8-$ & 2,17 & 2,48 & $1,66 \%$ & $1,25 \%$ & $1,01 \%$ & $0,93 \%$ & $0,83 \%$ \\
\hline 9 - & 3,89 & 4,37 & $0,14 \%$ & $0,19 \%$ & $0,48 \%$ & $0,42 \%$ & $0,38 \%$ & 9 - & 2,48 & 2,79 & $1,66 \%$ & $1,20 \%$ & $0,93 \%$ & $0,85 \%$ & $0,70 \%$ \\
\hline \multirow[t]{4}{*}{10 - } & 4,37 & - & $0,28 \%$ & $2,05 \%$ & $1,86 \%$ & $1,73 \%$ & $1,61 \%$ & $10-$ & 2,79 & 3,1 & $0,69 \%$ & $1,38 \%$ & $1,22 \%$ & $1,11 \%$ & $0,91 \%$ \\
\hline & & & & & & & & $11-$ & 3,1 & 3,41 & $1,11 \%$ & $0,69 \%$ & $0,62 \%$ & $0,59 \%$ & $0,55 \%$ \\
\hline & & & & & & & & $12-$ & 3,41 & 3,72 & $0,28 \%$ & $0,86 \%$ & $0,66 \%$ & $0,59 \%$ & $0,47 \%$ \\
\hline & & & & & & & & $13-$ & 3,72 & - & $0,83 \%$ & $2,18 \%$ & $2,13 \%$ & $1,93 \%$ & $1,52 \%$ \\
\hline \multicolumn{8}{|c|}{$\begin{array}{l}\text { Tempo necessário para atingir a metade do caminho em direção ao estado } \\
\text { estacionário (em anos) }=\ln (2) / \ln (\text { maior autovalor, exceto o unitário) }=30\end{array}$} & \multicolumn{8}{|c|}{$\begin{array}{l}\text { Tempo necessário para atingir a metade do caminho em direção ao estado } \\
\text { estacionário (em anos) }=\ln (2) / \ln (\text { maior autovalor, exceto o unitário })=44\end{array}$} \\
\hline \multicolumn{8}{|c|}{$1980-2006$} & \multicolumn{8}{|c|}{$1985-2006$} \\
\hline \multicolumn{3}{|c|}{$\begin{array}{c}\text { Classes de } \\
\text { Produtividade }\end{array}$} & (cad & período $\mathrm{s}$ & $\begin{array}{r}\text { Períod } \\
\text { e refere a }\end{array}$ & th & 26 anos) & & $\begin{array}{r}\text { Classes } \\
\text { Produtivi }\end{array}$ & $\begin{array}{l}\text { le } \\
\text { ade }\end{array}$ & (cada & período & $\begin{array}{r}\text { Períod } \\
\text { refere a }\end{array}$ & tervalo d & 21 anos) \\
\hline & $\mathrm{Li}$ & Ls & Inicial & 1 & 2 & 3 & $\begin{array}{c}\text { Estado } \\
\text { Estacionário }\end{array}$ & & $\mathrm{Li}$ & Ls & Inicial & 1 & 2 & 3 & $\begin{array}{c}\text { Estado } \\
\text { Estacionário }\end{array}$ \\
\hline $1-$ & - & 0,29 & $4,85 \%$ & $17,29 \%$ & $24,43 \%$ & $28,22 \%$ & $31,12 \%$ & $1-$ & - & 0,38 & $23,68 \%$ & $24,56 \%$ & $23,86 \%$ & $23,36 \%$ & $22,53 \%$ \\
\hline $2-$ & 0,29 & 0,57 & $19,11 \%$ & $24,85 \%$ & $24,81 \%$ & $23,90 \%$ & $23,05 \%$ & $2-$ & 0,38 & 0,75 & $36,29 \%$ & $30,06 \%$ & $29,49 \%$ & $29,20 \%$ & $29,01 \%$ \\
\hline $3-$ & 0,57 & 0,86 & $24,79 \%$ & $18,63 \%$ & $16,37 \%$ & $15,21 \%$ & $14,27 \%$ & $3-$ & 0,75 & 1,13 & $16,20 \%$ & $18,55 \%$ & $18,25 \%$ & $18,46 \%$ & $18,72 \%$ \\
\hline $4-$ & 0,86 & 1,14 & $18,56 \%$ & $12,44 \%$ & $10,48 \%$ & $9,83 \%$ & $9,37 \%$ & $4-$ & 1,13 & 1,51 & $7,76 \%$ & $11,37 \%$ & $11,80 \%$ & $12,06 \%$ & $12,34 \%$ \\
\hline $5-$ & 1,14 & 1,43 & $13,57 \%$ & $10,59 \%$ & $6,99 \%$ & $5,92 \%$ & $5,21 \%$ & $5-$ & 1,51 & 1,88 & $4,02 \%$ & $4,52 \%$ & $4,79 \%$ & $4,85 \%$ & $4,95 \%$ \\
\hline $6-$ & 1,43 & 1,72 & $8,45 \%$ & $4,11 \%$ & $4,29 \%$ & $4,34 \%$ & $4,45 \%$ & $6-$ & 1,88 & 2,26 & $2,91 \%$ & $3,19 \%$ & $3,34 \%$ & $3,47 \%$ & $3,59 \%$ \\
\hline $7-$ & 1,72 & 2 & $4,16 \%$ & $2,90 \%$ & $2,23 \%$ & $1,86 \%$ & $1,64 \%$ & $7-$ & 2,26 & 2,64 & $1,80 \%$ & $1,80 \%$ & $1,86 \%$ & $1,89 \%$ & $1,94 \%$ \\
\hline $8-$ & 2 & 2,29 & $3,19 \%$ & $2,04 \%$ & $2,63 \%$ & $2,86 \%$ & $3,03 \%$ & $8-$ & 2,64 & 3,01 & $1,39 \%$ & $1,12 \%$ & $1,21 \%$ & $1,23 \%$ & $1,26 \%$ \\
\hline 9 - & 2,29 & 2,57 & $1,39 \%$ & $0,71 \%$ & $1,23 \%$ & $1,24 \%$ & $1,20 \%$ & 9 - & 3,01 & 3,39 & $1,39 \%$ & $1,12 \%$ & $1,13 \%$ & $1,15 \%$ & $1,19 \%$ \\
\hline $10-$ & 2,57 & 2,86 & $0,69 \%$ & $0,88 \%$ & $0,77 \%$ & $0,71 \%$ & $0,67 \%$ & $10-$ & 3,39 & 3,77 & $0,69 \%$ & $0,90 \%$ & $0,96 \%$ & $0,97 \%$ & $0,99 \%$ \\
\hline $11-$ & 2,86 & 3,15 & $0,55 \%$ & $1,28 \%$ & $1,17 \%$ & $1,20 \%$ & $1,21 \%$ & $11-$ & 3,77 & 4,14 & $1,39 \%$ & $0,33 \%$ & $0,42 \%$ & $0,43 \%$ & $0,44 \%$ \\
\hline $12-$ & 3,15 & - & $0,69 \%$ & $4,31 \%$ & $4,60 \%$ & $4,71 \%$ & $4,79 \%$ & $12-$ & 4,14 & 4,52 & $0,28 \%$ & $0,17 \%$ & $0,21 \%$ & $0,21 \%$ & $0,22 \%$ \\
\hline & & & & & & & & $13-$ & 4,52 & 4,9 & $0,69 \%$ & $0,55 \%$ & $0,71 \%$ & $0,72 \%$ & $0,75 \%$ \\
\hline & & & & & & & & $14-$ & 4,9 & 5,27 & $0,14 \%$ & $0,17 \%$ & $0,16 \%$ & $0,17 \%$ & $0,17 \%$ \\
\hline & & & & & & & & $15-$ & 5,27 & 5,65 & $0,28 \%$ & $0,11 \%$ & $0,15 \%$ & $0,16 \%$ & $0,16 \%$ \\
\hline & & & & & & & & $16-$ & 5,65 & 6,03 & $0,14 \%$ & $0,00 \%$ & $0,00 \%$ & $0,00 \%$ & $0,00 \%$ \\
\hline & & & & & & & & $17-$ & 6,03 & 6,4 & $0,28 \%$ & $0,00 \%$ & $0,00 \%$ & $0,00 \%$ & $0,00 \%$ \\
\hline & & & & & & & & $18-$ & 6,4 & 6,78 & $0,14 \%$ & $0,15 \%$ & $0,12 \%$ & $0,11 \%$ & $0,11 \%$ \\
\hline & & & & & & & & $19-$ & 6,78 & - & $0,55 \%$ & $0,90 \%$ & $1,10 \%$ & $1,13 \%$ & $1,18 \%$ \\
\hline & $\begin{array}{l}\text { Tempo n } \\
\text { estacion }\end{array}$ & $\begin{array}{l}\text { sário } p \\
\text { (em an }\end{array}$ & $\begin{array}{l}\text { atingir a } \\
=\ln (2) / 1\end{array}$ & $\begin{array}{l}\text { netade do } \\
\text { (maior au }\end{array}$ & $\begin{array}{l}\text { caminho } \\
\text { tovalor, ex }\end{array}$ & $\begin{array}{l}\mathrm{n} \text { direção } \\
\text { to o unit }\end{array}$ & $\begin{array}{l}\text { o estado } \\
\text { rio) }=28\end{array}$ & & $\begin{array}{l}\text { Tempo ne } \\
\text { estacioná }\end{array}$ & $\begin{array}{l}\text { essário pa } \\
\text { o (em ano }\end{array}$ & $\begin{array}{l}\text { a atingir a } \\
)=\ln (2) / \ln \end{array}$ & $\begin{array}{l}\text { metade d } \\
\text { (maior at }\end{array}$ & $\begin{array}{l}\text { caminho } \\
\text { pvalor, ex }\end{array}$ & $\begin{array}{l}\mathrm{n} \text { direção } \\
\text { to o unit }\end{array}$ & $\begin{array}{l}\text { to estado } \\
\text { rio) }=28\end{array}$ \\
\hline & & & & & & & 199 & $96-2006$ & & & & & & & \\
\hline & & & & & $\begin{array}{l}\text { Classes } \\
\text { Produtiv }\end{array}$ & & (cada p & eríodo s & $\begin{array}{l}\text { Períod } \\
\text { se refere a }\end{array}$ & atervalo d & 11 anos) & & & & \\
\hline & & & & & $\mathbf{L i}$ & Ls & Inicial & 1 & 2 & 3 & $\begin{array}{l}\text { Estado } \\
\text { Estaciona }\end{array}$ & & & & \\
\hline & & & & $1-$ & - & 0,34 & $15,79 \%$ & $19,78 \%$ & $21,91 \%$ & $23,33 \%$ & $25,74 \%$ & & & & \\
\hline & & & & $2-$ & 0,34 & 0,67 & $30,61 \%$ & $29,58 \%$ & $30,93 \%$ & $31,58 \%$ & $32,35 \%$ & & & & \\
\hline & & & & $3-$ & 0,67 & 1,01 & $18,01 \%$ & $18,92 \%$ & $18,00 \%$ & $17,55 \%$ & $16,80 \%$ & & & & \\
\hline & & & & $4-$ & 1,01 & 1,34 & $11,77 \%$ & $12,65 \%$ & $11,98 \%$ & $11,45 \%$ & $10,59 \%$ & & & & \\
\hline & & & & $5-$ & 1,34 & 1,68 & $8,59 \%$ & $6,56 \%$ & $6,11 \%$ & $5,81 \%$ & $5,36 \%$ & & & & \\
\hline & & & & $6-$ & 1,68 & 2,01 & $5,54 \%$ & $3,91 \%$ & $3,35 \%$ & $3,10 \%$ & $2,75 \%$ & & & & \\
\hline & & & & $7-$ & 2,01 & 2,35 & $2,77 \%$ & $2,21 \%$ & $2,02 \%$ & $1,86 \%$ & $1,60 \%$ & & & & \\
\hline & & & & $8-$ & 2,35 & 2,68 & $1,80 \%$ & $1,44 \%$ & $1,24 \%$ & $1,17 \%$ & $1,07 \%$ & & & & \\
\hline & & & & 9 - & 2,68 & 3,02 & $1,52 \%$ & $1,09 \%$ & $1,02 \%$ & $0,98 \%$ & $0,90 \%$ & & & & \\
\hline & & & & $10-$ & 3,02 & 3,35 & $1,11 \%$ & $0,96 \%$ & $0,82 \%$ & $0,76 \%$ & $0,67 \%$ & & & & \\
\hline & & & & $11-$ & 3,35 & 3,69 & $1,25 \%$ & $0,75 \%$ & $0,65 \%$ & $0,62 \%$ & $0,58 \%$ & & & & \\
\hline & & & & $12-$ & 3,69 & 4,02 & $0,28 \%$ & $0,30 \%$ & $0,28 \%$ & $0,25 \%$ & $0,22 \%$ & & & & \\
\hline & & & & $13-$ & 4,02 & 4,36 & $0,28 \%$ & $0,29 \%$ & $0,25 \%$ & $0,24 \%$ & $0,23 \%$ & & & & \\
\hline & & & & $14-$ & 4,36 & 4,69 & $0,14 \%$ & $0,21 \%$ & $0,20 \%$ & $0,19 \%$ & $0,17 \%$ & & & & \\
\hline & & & & $15-$ & 4,69 & - & $0,55 \%$ & $1,36 \%$ & $1,23 \%$ & $1,12 \%$ & $0,97 \%$ & & & & \\
\hline & & & & & $\begin{array}{l}\text { Tempo ne } \\
\text { estacioná }\end{array}$ & $\begin{array}{l}\text { sário } \mathrm{p} \\
\text { (em ar }\end{array}$ & $\begin{array}{l}\text { atingir a me } \\
=\ln (2) / \ln (\mathrm{m}\end{array}$ & $\begin{array}{l}\text { tade do } \\
\text { naior au }\end{array}$ & $\begin{array}{l}\text { caminho } \\
\text { tovalor, ex }\end{array}$ & $\begin{array}{l}1 \text { direção } \\
\text { to o unit }\end{array}$ & $\begin{array}{l}\text { estado } \\
)=15\end{array}$ & & & & \\
\hline
\end{tabular}

Nota: $\mathrm{Li}=$ limite inferior; $\mathrm{Ls}=$ limite superior.

Fonte: Resultados da pesquisa. 
Outra questão que merece ser levada em consideração é: o critério de construção dos intervalos de classe influencia os resultados obtidos? Visando robustecer os resultados encontrados, a Figura 3 apresenta a distribuição, no estado estacionário, para a produtividade relativa da mão de obra na agropecuária dos municípios de Minas Gerais pelo método de Quah (1992), assumindo-se a existência de dez classes de produtividade, e Magrini (1999).

Como se depreende da análise da Figura 3, os resultados não sofrem alterações qualitativas quando se considera o método de Quah (1992) para a construção dos intervalos de classe. Em geral, os fenômenos de alta persistência e muni- cípios migrando para classes inferiores continuam a ocorrer, o que robustece os resultados encontrados.

Por fim, um último questionamento como teste de robustez dos resultados seria o seguinte: as conclusões obtidas com os resultados até aqui encontrados sofrem alterações se janelas de transição intermediárias são levadas em consideração? Ou seja, ao se considerar transições entre os períodos de 1970 a 1975, 1970 a 1980, 1970 a 1985, 1970 a 1996 e assim por diante, haverá alterações qualitativas nos resultados reportados?

Os dados da Figura 4 buscam elucidar esta questão ao se considerarem diversas janelas de transição intermediárias, apresentando as dis-

Figura 3. Comparativo entre a distribuição no estado estacionário para a produtividade relativa da mão de obra na agropecuária dos municípios de Minas Gerais pelo método de Quah (1992) e Magrini (1999) no período de 1970 a 2006 (a), 1975 a 2006 (b), 1980 a 2006 (c), 1985 a 2006 (d) e 1996 a 2006 (e)
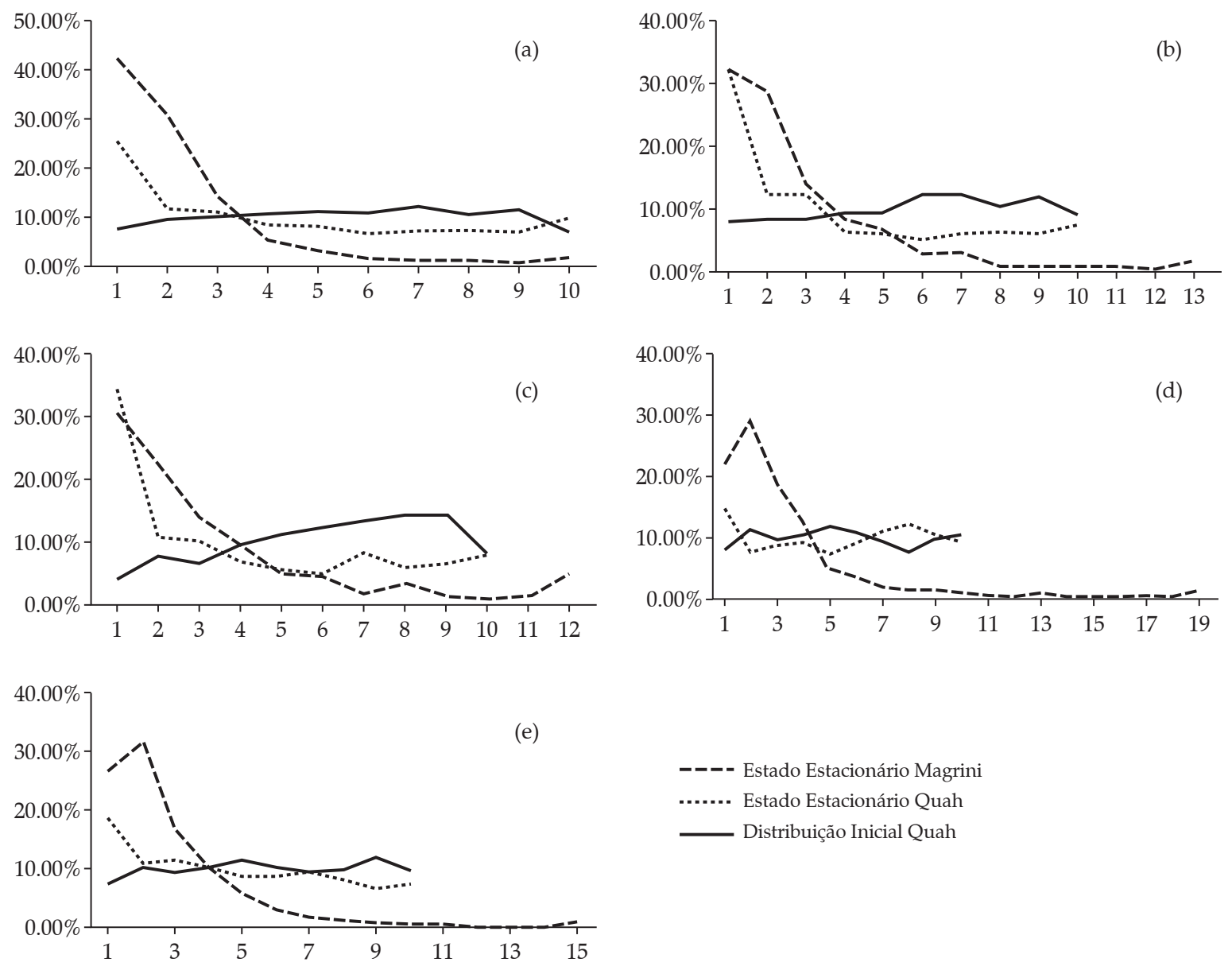

Fonte: Resultados da pesquisa. 
Figura 4. Distribuição inicial e do estado estacionário para janelas de transição intermediárias pelo método de Quah (1992) com período inicial de 1970 (a), 1975 (b), 1980 (c) e 1985 (d)

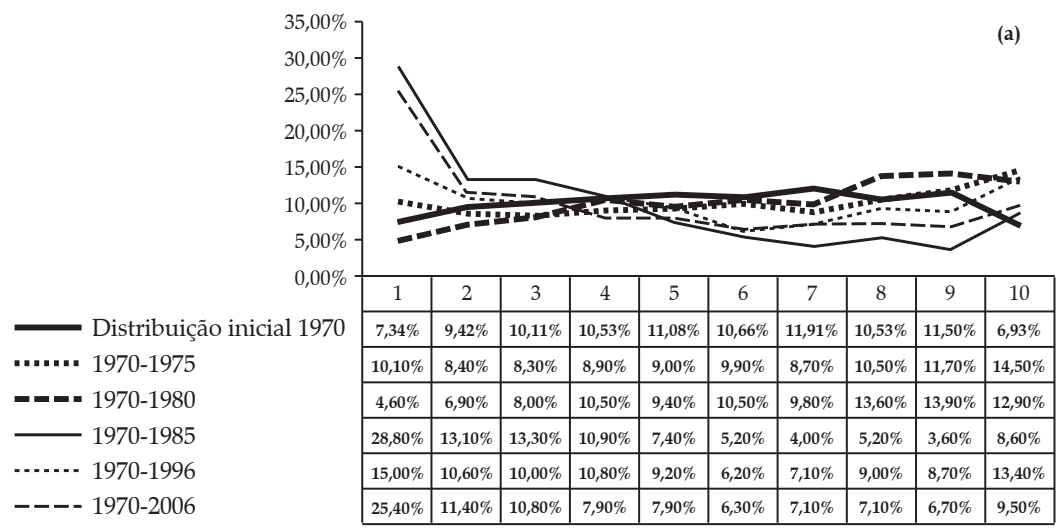
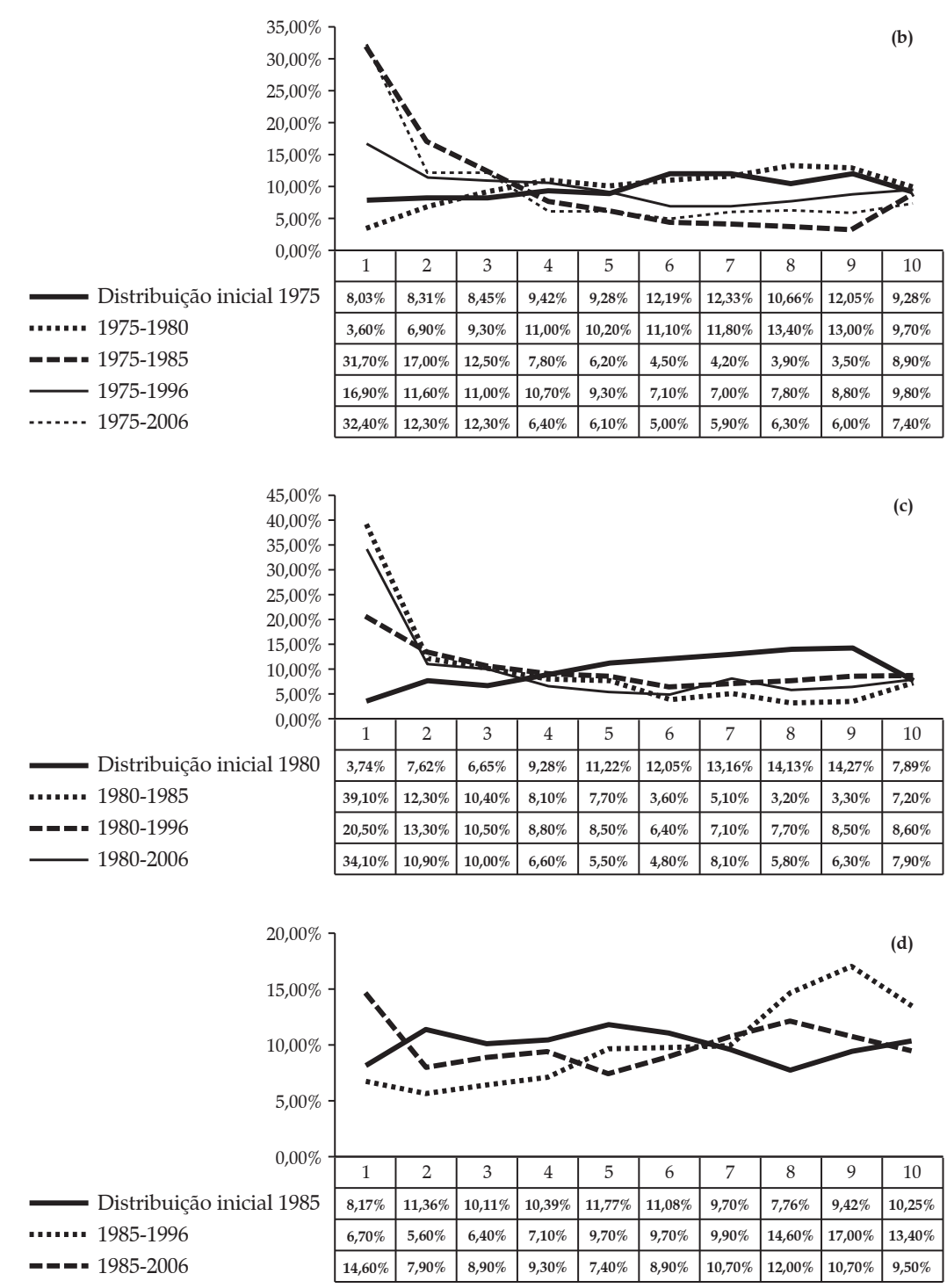

Fonte: Resultados da pesquisa. 
tribuições iniciais e do estado estacionário, com seus respectivos valores, utilizando-se o método de Quah (1992) e levando-se em consideração a existência de dez classes de produtividade.

Como se depreende da análise da Figura 4, a única alteração qualitativa significativa ocorre na janela de transição 1985 a 1996 reportado pelo painel (d). Nota-se que essas alterações ocorrem nas classes um e dez. Com relação à classe um, a transição 1985-1996 previa, no estado estacionário, que 6,70\% dos municípios estariam nesta classe, enquanto que a transição 1985-2006 previa $14,60 \%$. Dado que, em 1985, 8,17 \% dos municípios estavam, de fato, nesta classe, tem-se que, dependendo da janela de transição adotada, pode-se inferir aumento ou decréscimo de municípios que migram para a classe um. O mesmo ocorre com a classe dez, só que, desta vez, em um movimento contrário. Ao se adotar a janela de transição 19851996, chegar-se-ia à conclusão de que, no estado estacionário, haveria um aumento de municípios que migrariam para esta classe, o contrário ocorrendo para a janela de transição 1985-2006.

Em outras palavras, o fato de se estender a janela de transição em dez anos gerou mudanças qualitativas nos resultados. Como a metodologia é, basicamente, de descrição da evolução da distribuição da produtividade, qualquer tentativa de fornecer explicações, neste contexto, seriam meramente especulações. O fato é que algum choque estrutural ocorreu sobre o setor agropecuário mineiro, no período pós-1996, que foi capaz de gerar mudanças qualitativas nas duas classes extremas retro mencionadas.

\section{Conclusões}

As disparidades regionais existentes no estado de Minas Gerais são um fato notadamente reconhecido e documentado, situação que se estende ao seu setor agropecuário. À luz desse contexto e do recente bom desempenho produtivo desse setor, este trabalho procurou investigar se existe alguma tendência para que a distância entre regiões agropecuárias de elevada e baixa produti- vidade venha a diminuir, tomando por base o período compreendido entre 1970 e 2006. Para tanto, utilizou-se como variável de análise a produtividade relativa da mão de obra na agropecuária dos municípios do estado, buscando avaliar a existência ou não de um processo de convergência sob a ótica de diferentes metodologias de teste.

Os resultados encontrados demonstram que a densidade de distribuição sofreu, ao longo do período de estudo, um deslocamento de massa para a esquerda, denotando uma piora em sua distribuição de produtividades. Quanto à sua dinâmica, esboçada pelo cálculo das matrizes de Markov, nota-se uma trajetória de transição que converge para as classes inferiores de produtividade. Outro ponto a se destacar é que, no estado estacionário, a maior parte dos municípios situa-se em classes de produtividade que estão abaixo da média do estado.

Conclui-se, assim, que o crescimento econômico não está sendo capaz de reduzir as diferenças regionais, segundo o que apontam as metodologias propostas, e que as políticas públicas direcionadas ao setor deveriam ser revistas, visando não somente ao crescimento da produção.

A principal deficiência da presente pesquisa está em seu caráter predominantemente descritivo e não tão explicativo. Essa é uma lacuna que futuros trabalhos poderão preencher mediante o uso de esquemas condicionantes, que são capazes de mensurar como determinadas variáveis afetam a distribuição de produtividades, bem como sua probabilidade de transição. Com isso, será possível identificar quais as principais variáveis responsáveis por influenciar positivamente a trajetória de crescimento da produtividade.

\section{Referências bibliográficas}

ALVES, L. F. e FONTES, R. Clubes de convergência entre os municípios de Minas Gerais. Revista Econômica do Nordeste, v. 32, n especial, 2001, p. 546-568.

BULLI, S. Distribution dynamics and cross-country convergence: a new approach. Scottish Journal of Political Economy, v. 42, p. 226-243, 2001. 
CALDEIRA, T. A.etal. Educação, Crédito e Convergência de Renda Agropecuária em Minas Gerais. In: XIV Seminário sobre a Economia Mineira, 2010, Diamantina, MG. Anais... Diamantina: CEDEPLAR, 2010. p.1-20.

CURI, W. F. Eficiência e fonte de crescimento da agricultura mineira na dinâmica de ajustamento da economia brasileira. 1997. Dissertação (Mestrado em Economia Aplicada) Universidade Federal de Viçosa, Viçosa, MG.

DRENNAN, M. P. e LOBO, J. A Simple Test for Convergence of Metropolitan Income in the United States. Journal of Urban Economics, n. 46, p-350-359, 1999.

FERREIRA JÚNIOR, S. et al. A modernização agropecuária nas microrregiões do estado de Minas Gerais. Revista de Economia e Sociologia Rural, Brasília-DF, v. 42, n. 1, p. 271-290, 2004.

FIGUEIRÊDO, L., LEAL FILHO, R. S. e AGUIAR, C. Matriz de Probabilidades de Transição por Estimador de Núcleo para as Rendas Relativas das Microrregiões de Minas Gerais. In: XIV Seminário sobre a Economia Mineira, 2010, Diamantina, MG. Anais... Diamantina: CEDEPLAR, 2006. p.1-20.

FOCHEZATTO, A. e STULP, V. J. Análise de convergência da produtividade da mão-de-obra agropecuária entre os estados brasileiros: aplicação de matrizes de Markov, 1990-2000. Revista de Economia e Sociologia Rural, v. 46, n. 3, p. 739-765, jul./set. 2008.

FREITAS, C. A., BACHA, C. J. C. e FOSSATTI, D. M. Avaliação do desenvolvimento do setor agropecuário no Brasil. Economia e Sociedade (UNICAMP), v. 16, n. 1, p. 111-124, 2007.

GASQUES, J. G. e CONCEIÇÃO, J. C. P. R. Transformações estruturais da agricultura e produtividade total dos fatores. Brasília: IPEA, 2000. (Texto para Discussão, 768).

et al. Condicionantes da produtividade da agropecuária brasileira. Brasília: IPEA, 2004. (Texto para Discussão, n. 1017).

GOLLIN, D., PARENTE, S. e ROGERSON, R. The Role of Agriculture in Development. The American Economic Review, v. 92, n. 2, p. 160-164, 2002.

GONÇALVES, J. S. Crescimento do produto e conteúdo da produtividade na agropecuária brasileira do período 1975-2003. Informações Econômicas, v. 37, n. 8, 2007.

GONDIM, J. e BARRETO, F. A. O uso do núcleo estocástico para identificação de clubes de convergência entre estados e municípios brasileiros. In: ENCONTRO NACIONAL DE ECONOMIA, 32, 2004, Salvador. Anais... Salvador: ANPEC, 2004. p. 1-15.
INSTITUTO DE PESQUISA ECONÔMICA APLICADA - IPEA. Conta Nacionais. 2009. Disponível em: <www. ipeadata.gov.br>. Acesso em: 20 jul. 2011.

JONES, C. I. Introdução à teoria do crescimento econômico. Rio de Janeiro: Elsevier, 2000.

LE GALLO, J. Space-time analysis of GDP disparities among European regions: a Markov chains approach. Dijon/França: University of Burgundy, Mar. 2001.

MAGRINI, S. The evolution of income disparities among the regions of the European Union. Regional Science and Urban Economics, v. 29, p. 257-281, 1999.

MEYER, L. F. F. e BRAGA, M. J. O crescimento das desigualdades tecnológicas na agricultura mineira. Revista de Economia e Sociologia Rural, Brasília, v. 36, n. 01, p. 59-90, 1998.

PIMENTEL, E. A. e HADDAD, E. A. Análise da distribuição espacial da renda no Estado de Minas Gerais: uma abordagem setorial. São Paulo: Nereus, 2004 (Texto para Discussão $n^{\circ}$ 02-2004).

QUAH, D. Empirical cross-section Dynamics in Economic Growth. LSE Working Paper, 1992.

. Galton's fallacy and testes of the convergence hypothesis. Scandinavian Journal of Economics, v. 95, n. 4, p. 427-443, 1993.

Empirics for growth and distribution: stratification, polarization and convergence clubs. Journal of Economic Growth, v. 2, n. 1, p. 27-59, 1997.

SALVATO, M. A. et al. Disparidades Regionais em Minas Gerais. In: XIV Seminário sobre a Economia Mineira, 2006, Diamantina, MG. Anais... Diamantina: CEDEPLAR, 2006. p.1-20.

SECRETARIA DE ESTADO DE AGRICULTURA, PECUÁRIA E ABASTECIMENTO. (SEAPA). Disponível em: <http://www.agricultura.mg.br>. Acesso em: 20 ago. 2010.

SILVA, E., FONTES, R. e ALVES, L. F. Crescimento e Desigualdade em Minas Gerais. In: FONTES, R. e FONTES, M. (Eds.). Crescimento e Desigualdade Regional em Minas Gerais. Viçosa: Editora Folha de Viçosa, 2005.

SIMON, C. P. e BLUME, L Matemática para Economistas. Porto Alegre: Bookman, 2004.

STULP, V. J. Evolução Regional da Produtividade da Mão-de-Obra na Agropecuária Gaúcha: uma Aplicação da Matriz de Markov. Revista de Economia e Sociologia Rural, v. 42, n. 02, p. 293-316, 2004. 
800 - Qual a Direção da Convergência na Produtividade da Mão de Obra na Agropecuária de Minas Gerais?

VICENTE, J.R. Comparação da produtividade agrícola entreas unidades da federação, 1970-1995. Disponível em: <http:// www.iea.sp.gov.br/out/verTexto.php?codTexto $=8083>$. Acesso em: 10 fev. 2009.
YANG, D. T. e ZHU, X. Modernization of agriculture and long-term growth. Disponível em: <http://www.gsm. pku.edu.cn/UserFiles/0708-28(6).pdf>. Acesso em: 19 fev. 2009. 